\title{
Festival Folclórico de Parintins: um estudo sobre a presença indígena na composição das toadas e a produção do cenário artístico apresentado no bumbódromo (1995-2010)
}

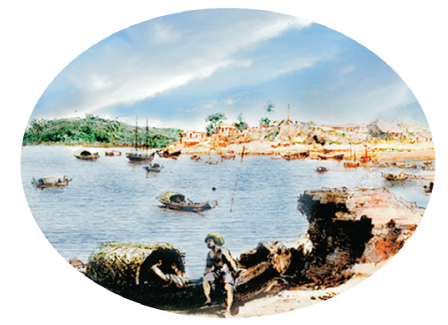

Socorro de Souza Batalha*

\section{Resumo}

Este trabalho tem como universo de pesquisa a presença indígena nos bumbás de Parintins (Garantido e Caprichoso). Nele discuto o processo de criação das toadas e a produção do cenário artístico apresentado através dos rituais no bumbódromo. O ritual é um dos momentos que antecede a chegada do pajé, uma dramatização evidenciando a vida das etnias indígenas, no qual são vistas alegorias, indumentárias, itens individuais e grupais. Os dados da pesquisa foram reunidos a partir do levantamento das letras escritas no período 1995-2010 e levando em conta o questionamento sobre a invenção dos compositores e artistas alegóricos, por meio tanto de entrevistas realizadas com estes quanto de depoimentos colhidos dos membros da Comissão de Artes, do boi Garantido e do Conselho de Arte, do boi Caprichoso. Nesse sentido, identifiquei as etnias mais citadas nas letras das toadas, destacando o cenário alegórico visto pelos compositores e os mitos referendados nos rituais durante as apresentações dos bumbás. Em torno disso, tecerei relações entre o método criativo dos compositores e com espetáculo artístico.

Palavras-chave: Boi-Bumbá; indígenas; Parintins.

\section{Abstract}

This work has the universe for the indigenous presence in bumbás Parintins (Guaranteed and Capricious), it discuss the process of creating melodies and production art scene through the rituals presented in bumbódromo. The ritual is one of the moments before

*Cientista Social na Ufam e mestranda do Programa de Pós Graduação em Antropologia Social na mesma instituição. 
the arrival of the shaman, a dramatization showing the lives of indigenous groups, which are seen allegories, costumes, individual and group items. Survey data were gathered from a survey of letters written in the period 1995-2010 and taking into account the questioning about the invention of the composers and artists allegorical, both through interviews with them as testimonies collected from members of the Arts, the ox and the Guaranteed Arts Council, ox Capricious. In this sense, the ethnic groups identified most frequently cited in the lyrics of the chants, highlighting the scenario seen by composers and allegorical myths referenced in rituals during presentations of bumbás. Around that, I shall make a relationship between the method of creative composers and artistic spectacle.

Keywords: Boi Bumba; Indigenous; Parintins

\section{Introdução}

Este artigo é fruto de uma pesquisa realizada no trabalho de conclusão do curso sobre a presença indígena nas toadas dos rituais no Festival Folclórico de Parintins, na qual elenquei, sobretudo, o processo de criação dos compositores, seus arranjos e parceria. ${ }^{1}$ No desenvolver do trabalho, verifiquei que as toadas e alegorias ${ }^{2}$ são modalidades que formam o embasamento do festival.

A cidade de Parintins tornou-se conhecida, nacionalmente, devido à realização do Festival Folclórico de Parintins, que se baseia na disputa dos bumbás: Garantido, o "boi vermelho" e Caprichoso, o "boi azul”. Enquanto o primeiro possui um coração na testa, o segundo possui uma estrela. A competição acontece em três dias de festa que atualmente é no último fim de semana do mês de junho.

Há muita controvérsia sobre a fundação dos bumbás, mas vigora que ambos foram fundados em 1913. Segundo registros bibliográficos, ${ }^{3}$ o Boi Caprichoso foi fundado pelos irmãos Cid e Luiz Gonzaga. Ao longo dos anos, o boi foi dirigido por várias famílias e suas apresentações aconteciam em diferentes currais ${ }^{4}$ nos bairros da cidade. $O$ fundador do Garantido foi Lindolfo Monteverde, que permaneceu na direção de 1913 até 1982. As performances ${ }^{5}$ do boi aconteceram em apenas um bairro da cidade de Parintins e, mais especificamente, no "curral" localizado no bairro "Baixa do São José".

A festa ganhou espaço entre o público, torcedores e brincantes, que foram se dividindo e optando pela adesão entre o Boi Garantido e o Boi Caprichoso, criando, assim, uma rivalidade que ultrapassou os limites da 
própria brincadeira. Dessa forma, quando os bois se encontravam nas ruas de Parintins ninguém queria sair derrotado, o verso ${ }^{6}$ de afronta sempre gerava atrito, sempre resultando em brigas entre os brincantes. Cavalcanti enfatiza (1999) "Os bois brincavam em terreiros e saíam nas ruas onde se confrontavam com desafios e invitáveis brigas, pois quando se encontravam, nenhum queria deixar o outro passar, ou voltar para trás".

Em meados de 1960 no mês de junho, nas ruas da cidade, os dois bois disputavam em vários lugares em Parintins. Foi exatamente nessa década que se oficializou o primeiro Festival Folclórico de Parintins, no ano de 1966. As competições tornaram-se mais intensas e os bumbás ganharam simpatia do público, autonomia e popularidade dos torcedores que vinham prestigiar a festa. Com a construção do bumbódromo, em 1988, os bois passaram a competir nos dias 28, 29 e 30 de junho. ${ }^{7}$ Em 2005 uma lei municipal apoiada pelos presidentes dos bumbás e pela comunidade estabeleceu que o Festival Folclórico de Parintins realizar-se-ia no último fim de semana do mês de junho, como vem ocorrendo até os dias de hoje.

As toadas para apresentação do espetáculo passam por um processo de seleção. Tal certame é realizado pela Comissão de $\operatorname{Artes}^{8}$, no caso do "boi" Garantido; e pelo Conselho de Artes", no caso do "boi" Caprichoso. Em ambos os casos, participam desse processo: compositores, arranjadores e convidados. Anualmente, inúmeras toadas são apresentadas pelos compositores à Comissão de Artes e ao Conselho de Artes. Estes realizam um procedimento seletivo no qual são escolhidas as toadas que estão de acordo com o enredo do "boi" a ser exibido na arena. Em grande parte do espetáculo, as encenações são feitas mencionando algumas etnias, que são expostas por meio das toadas, coreografias e cenário no bumbódromo.

Além disso, no referido festival são apresentados aspectos e personagens que lembram o cenário do cotidiano amazônico, tais como: o chamado "caboclo ribeirinho", lenda amazônica, figura típica regional, ritual, dentre outros. Nesse contexto, percebe-se fortemente a figura do indígena e, por esse motivo, esta pesquisa terá como escopo principal analisar a forma como a cultura indígena está sendo apresentada (ou representada) aos espectadores no decorrer do festival, tendo como foco seus rituais, bem como o processo criativo dos compositores e artistas plásticos. 


\section{A presença indígena/criar e cantar com os bois de Parintins}

A ênfase da temática indígena se tornou mais frequente nos itens toada, coreografia e alegoria na década de 1990 (CAVALCANTI, 1999). Nessa perspectiva, as mudanças em torno das apresentações principalmente nessa década, ${ }^{10}$ foram fundamentando uma nova forma de exposição no que diz respeito à figura do indígena no festival. A presença do pajé, por exemplo, que antes acontecia somente para reviver o boi, agora se configura num novo momento, chamado ritual. O pajé surge para encenar uma luta entre o bem e o mal, combatendo um espírito aterrorizante de um determinado grupo indígena. Dessa forma, Valentin (2006) enfatiza:

O final da apresentação de cada Boi é marcada por uma encenação apoteótica, o ritual. Para servir de palco e cenário para uma estória cujo tema central é sempre a luta do bem contra o mal, no centro do bumbódromo um enorme cenário é montado, através de módulos que vão sendo armados na arena. Ali, sob efeitos especiais, luzes e fogos, centenas de figurantes desenrolam momentos de intensa dramaticidade. O pajé, com suas sofisticadas fantasias e complexas coreografias, é o ator principal, o herói dessa epopeia amazônica (VALENTIN, 2006, p. 47).

Nas três noites do festival são apresentadas toadas que narram mitos indígenas para acompanhar a aparição do pajé no momento do ritual, sempre relatando catástrofes sobre determinados povos indígenas. A característica do ritual é marcada por certos personagens como: pajé, tribos, seres fantasmagóricos, danças e animais que promovem a luta entre o bem e o mal.

Antes de especificar como ocorre o processo de escolha das toadas supervisionadas pela Comissão de Artes do Boi Garantido e pelo Conselho de Artes do Boi Caprichoso, acho necessário enfatizar o que é "toada" no contexto do festival folclórico de Parintins. Na verdade, são composições musicais elaboradas para os bumbás e nelas encontram-se versos para o tema escolhido durante o ano para ser apresentado na arena do bumbódromo. Fazem referência aos itens individuais e grupais. A respeito das toadas, Braga (2002) comenta. 
As toadas são resultantes de um longo processo, que se inicia com a criação artística do compositor, tem continuidade na seleção da toada pelo Boi-Bumbá e na interpretação recebida do Levantador de toadas, quando este contribui na apresentação das músicas do Boi-Bumbá no Festival e concorre ao item toadas nas três noites do espetáculo. Em todos esses momentos, os brincantes permanecem atentos, pois são eles quem em última instância definem a preferência ou gosto musical das toadas (BRAGA, 2002, p. 57).

As toadas são elaboradas por vários compositores que em sua maioria residem em Parintins e outros em Manaus. Suas criações visam às apresentações na arena do bumbódromo. Os compositores não podem escrever suas criações no mesmo ano para ambos os bumbás, isto é, eles têm de escolher um para concorrer. Nesse âmbito, pode acontecer do compositor fazer alternância para compor para ambos os bumbás, ou seja, em um ano ele compõe para um boi e no ano seguinte para outro boi.

No boi Garantido, o processo de seleção das toadas dos rituais é feito pela Comissão de Artes, que submete-se um colegiado formado por mais ou menos trinta pessoas vinculadas ao conselho fiscal, conselho de ética, diretoria, comissão de artes e convidados. O conselho de artes do boi Caprichoso, composto em media por trinta integrantes, tem como propósito selecionar três toadas para as três noites de apresentações. As toadas criadas pelos compositores são direcionadas a um item, conforme as exigências do edital divulgado pelas agremiações. Fred Góes, integrante da comissão de artes do Garantido, que também é músico e compositor enfatiza os critérios estabelecidos pela comissão no processo de escolha das toadas. Nesse âmbito diz:

Ninguém determina nada: o compositor fica "livre" para compor, ele faz sua composição em função da toada e também em torno da etnia que proporciona mais elementos para pensar no cenário, que será posteriormente, é claro depois da aceitação da Comissão de Artes, apresentado na arena do bumbódromo. A Comissão de Artes espera o compositor apresentar a toada e, através dela escolhe o tema para ser apresentado no bumbódromo e para ser 
tralhado no período que antecede o Festival Folclórico de Parintins. Quando o compositor apresenta uma toada de um ritual de etnias do rio Madeira, o boi volta o seu trabalho para as etnias do rio Madeira, se compositor apresentar toadas de etnias do rio Negro, a estrutura do boi de arena será montada de acordo com essa região do rio Negro (Entrevista de campo, maio de 2011).

Zandonaide Bastos, membro do conselho de Artes e da equipe de pesquisa do boi Caprichoso, esclarece os critérios instituídos pelo conselho visando à apresentação na arena do bumbódromo, dizendo:

No Caprichoso é o Conselho que cria o tema, esse universo é resultante de várias pesquisas, que tem a proporção de encaixar novas propostas para as três noites. Então quando achamos a linha de pensamento que é justamente noite $\mathrm{A}$, noite $\mathrm{B}$ e noite $\mathrm{C}$ que são os subtemas, aí chamamos os compositores e repassamos nossa proposta. O conselho traça a linha de pensamento dentro do projeto e, os compositores vão trazendo. Na verdade, é o Conselho de Artes que determina a etnia que o compositor vai trabalhar (Entrevista de campo, maio de 2011).

De acordo com os depoimentos dos integrantes dos bois em questão Fred Góes e Zandonaide Bastos, podemos observar que os critérios de escolhas das toadas não se processam do mesmo modo, ou seja, cada boi estabelece seus critérios, que estão relacionados ao projeto do boi de arena. Enquanto o Boi Garantido escolhe o tema depois da seleção de toadas, o Boi Caprichoso faz o contrário, primeiro elabora a pesquisa e, em seguida, estabelece as etnias que o boi e os compositores irão trabalhar durante o ano para as apresentações do festival.

Investigar o processo que envolve a criação da toada é uma situação bastante peculiar para o pesquisador no que tange a compreensão do processo criativo e suas várias nuances (pesquisa, síntese, escrita etc.), pois se trata de um jeito particular do compositor a respeito da elaboração do trabalho. Atualmente, as pesquisas realizadas pelos compositores sobre as etnias levam em consideração elementos que possam ser atrativos para o público, por 
exemplo, A toada "Mawirin" - 2004, autoria de Ademar Azevedo, David Jerônimo e Elaine Rodrigues. A utilização de etnias indígenas nas toadas e consequentemente o uso de cores, danças, vestimentas, plumárias, pinturas corporais tem um propósito de trazer um plano visual durante as apresentações.

Partindo da premissa de que o Festival Folclórico de Parintins é um evento que, seguindo a linha de pensamento de Geertz (1997), materializa, através da visualização, um modo de viver o cotidiano na cidade, tal festival é também uma possibilidade para que o expectador se permita passar por experiências sonoras, e as toadas permitem isso. No entanto, tal como citado, o espetáculo visual deve estar associado com a letra da toada. Sendo assim, a evolução do boi na arena só será satisfatória caso a toada cite em sua letra elementos que deem abertura aos artistas que trabalham nos galpões, para que esses usem a criatividade a fim de representar na arena as etnias presentes nas toadas. Não obstante, isso só será possível mediante prévia pesquisa realizada pelo compositor antes de escrever a letra.

Partindo dessas perspectivas, faço uma relação com o trabalho de Menezes Bastos (1996), "Origem do samba como invenção do Brasil”. Sua análise se dá mediante a música "Feitio de Oração", autoria de Noel Rosa e Vadico. Menezes Bastos (1996), citando Máximo e Didier (1990), enfatiza que no processo de criação dos autores citados ocorreu um fato interessante: quando Vadico tocou a composição instrumental para Noel Rosa, na medida em que este foi ouvindo, foi desenhando um "monstro", isto é, um rascunho do que posteriormente seria a letra da canção o "Feitio de Oração". Nesse viés, o autor diz:

Quando Vadico tocou pela segunda vez sua música I, Noel, desde o início gravemente atento, pegou papel e lápis e começou a trabalhar um "monstro", isto é, "uma letra provisória destinada apenas a assinalar o número de sílabas de cada frase musical, a pontuação e a acentuação que deve ter cada uma” (MÁXIMO \& DIDIER, op. cit.). Ao final do encontro, Noel disse que iria tentar a letra, a qual apresentaria a Vadico dois dias depois, no mesmo estúdio da Odeon. Vadico a aceitou entusiasticamente, tendo início, assim, uma parceria fecunda entre os dois (MENEZES BASTOS, 1996, p. 8). 
Esse exemplo é típico na produção de muitas músicas (letra mais som instrumental). No entanto, no caso do processo criativo dos compositores que produzem para os bumbás do Festival Folclórico de Parintins, pelo mesmo segundo essa logística, os procedimentos são diferenciados: primeiramente o compositor faz a pesquisa da etnia, depois elabora a letra da toada, e em seguida fundamenta o arranjo.

Menezes Bastos (1996) ressalta em seu texto que quando Noel Rosa elaborou a letra da canção a partir de um "monstro", este era o número de sílabas que iria compor cada verso da música. Fazendo um comparativo com o processo de criação dos compositores do Festival Folclórico de Parintins, estes verificam de início os elementos que as etnias possuem para depois escreverem as letras das toadas. Sendo assim, se o arranjo foi fundamental para que Noel Rosa produzisse o "monstro" e posteriormente escrevesse a letra, para o compositor de toadas pensadas para o festival citado, a pesquisa torna-se fundamental. Sem ela não há letra e sem letra não há cenários.

O parâmetro usado pelos compositores no momento de inspiração mediante a citação de uma determinada etnia reside justamente na capacidade desta apresentar uma determinada quantidade de elementos que possam ser aproveitados com êxito na encenação do boi de arena. Elementos entre os quais, plumárias, pinturas corporais, movimentos de dança, vestimentas, adornos e artefatos, quanto mais coloridos melhor para o processo de composição, pois aumenta a possibilidade de tal etnia ser citada na letra da toada. Diante desse aspecto, Inaldo Medeiros ${ }^{11}$ diz: "Agora o compositor virou um pesquisador, a Comissão de Artes é uma quadrilha de artistas".

Os compositores criam canções individualmente ou em parcerias que se formam a partir da aliança de parentes consanguíneos e amigos cujas relações foram estabelecidas há algum tempo. Segundo informação dos compositores adquirida na pesquisa de campo, na maioria das vezes a parceria acontece quando alguém tem uma pesquisa sobre uma determinada etnia. Desse material resulta a elaboração da letra e posteriormente a criação do arranjo.

Dessa maneira, Fred Góes fundamenta essa questão sobre o processo de criação afirmando que o "compositor vai atrás das etnias capazes de fornecer mais rendimentos para a composição do cenário, porque a alegoria é um elemento primordial no julgamento do festival e, o compositor tem consciência desse critério" (Entrevista de campo, maio de 2011). 
O cenário que Fred Góes se refere é constituído por alegorias que são montadas na arena do bumbódromo no momento da apresentação.

Tem compositor que manda ideia de cenário, porque tem a visualização do que será apresentado na arena. Hoje, o festival está ficando que nem o futebol, todo mundo quer ser técnico no time, o festival está exatamente assim, todo mundo acha que tem uma idéia para montar um boi para ganhar o festival. O compositor está muito focado nessa ideia no procedimento de construção da toada, enfatiza ainda, que cada pessoa, sendo compositor, coreógrafo e arranjador têm uma visão, esta por se só, é apresentada à Comissão de Artes, com intuito de constituir o boi de arena (Entrevista de campo, maio de 2011).

Essas informações indicam a fundamentação de suas ideias sobre os compositores que compõem para boi de arena e, mais especificamente, sobre o procedimento de criação das toadas. Porém, vale atentar, também, para a questão dos elementos identificados pelos compositores que estão presentes nas etnias pesquisadas. De forma bem sucinta pontuarei o processo criação de duas toadas para arena do bumbódromo. Elas são: "Tucano" autoria de Inaldo Medeiros e Mencius Melo (1995), presente do CD "Uma Viagem a Amazônia” - Boi Garantido; "Mawirin” autoria de Azemar Azevedo (2004) presente no CD "Amazonas, Terra do Folclore, Fonte de Vida" - Boi Caprichoso.

$\mathrm{Na}$ toada "Tucano", Mencius Melo escreveu com Inaldo Medeiros, seu amigo de infância e aliado político na época da mudança do boi de arena. Ele estendeu laços com Inaldo Medeiros no fim da década de 1990 devido às discussões em torno da profissionalização do boi, ocorrido depois do advento do bumbódromo. No período de composição da toada "Tucano", Mencius estava lendo a poesia sobre o realismo fantástico de Gabriel Garcia Márquez. A pesquisa deu-se em cima de um conto Tucano que o compositor encontrou no jornal "Amazonas em tempo". Era uma lenda sobre o surgimento de um único ser Tucano, que dava origem a outros animais, como podemos observar na letra a seguir. 
Kaini ê, ê, ê, Kaini ê, ê, ê á

Kaini ê, ê, ê, Kaini ê, ê, ê á

Os ossos da força do vento

Voando rasteiro sobre o temporal

É herança de um povo guerreiro

$\mathrm{Na}$ luta da terra do bem e do mal

É a noite, é a lua, é a fecha, o pajé

São os ritos Tukano Nyê

É o fogo que queima no tempo dos tempos

Pra arte da guerra vencer

Hei, hei, hei

Kaini ê, ê, ê, Kaini ê, ê, ê á

Kaini ê, ê, ê, Kaini ê, ê, ê á ${ }^{12}$

A toada foi elaborada em um contexto no qual Mencius precisava manter seu posicionamento diante de uma conjuntura política, pois naquele período os grupos disputavam e marcavam território a fim de fixar posições de "quem manda mais no boi". Sendo assim, Mencius informou que criou as toadas mais por questões políticas; utilizando conteúdos musicais como um instrumento de legitimação no âmbito político na ala dos compositores. Mencius enfatizou, ainda, que naquela época o Boi não possuía estúdio e nem sequer exigia arranjos. Nessa fase, os instrumentos utilizados eram a caixinha, o surdo, a palminha, o xeque xeque, o repique e o violão. Nesse parâmetro, o compositor diz:

A única coisa que fiz foi a melodia, a música, a nota, a letra. O Boi se encarregou de fazer o arranjo em um estúdio em Manaus chamado Atração Fonográfica, contratado por Tony Medeiros. Ao contrário de agora de 2000 para cá, o boi passou exigir algo mais elaborado, ou seja, todo o arranjo para o Boi de arena, que acho injusto para as pessoas que não tem condições para montar a toada de estúdio, estes, não tem a mínima chance para concorrer. (Entrevista de campo, dezembro 2011).

Na toada "Mariwin", de autoria de Ademar Azevedo, David Jerônimo e Elaine Rodrigues, produzida em 2004, faz referência ao ritual indígena da 
etnia dos Matis localizados no Vale do Javarí. Os compositores se valeram das informações sobre a etnia publicadas no site do Instituto Socioambiental ISA. A toada começou a tomar corpo ainda durante a pesquisa com os arranjos de Ademar, considerado bom manipulador de violão. E nesse processo ele e seus parceiros foram inserindo melodia, arranjo e letra. Ademar Azevedo diz:

A criação ocorreu aos poucos, eu criava uma parte e David outra. Nesse processo de construção, eu fiz o início e o fim da toada e David o meio, depois juntamos as partes. O espaço físico que resultou a canção aconteceu em dois lugares: o meio da toada foi criado na sala de audiência do tribunal de justiça e o inicio e o fim na minha casa. Para ideia inicial, imaginei o cenário na arena do bumbódromo com a trilha sonora de estorros de onças e, o Mariwin vindo pelo meio da alegoria (Entrevista de campo, setembro 2011).

Na composição da letra da toada "Mariwin", ele utilizou papel, caneta, lápis, borracha e folha de processo sem serventia do Tribunal de Justiça. Depois passou o resultado para o computador. Azevedo, ao falar do processo de composição, fez o seguinte relato:

Quando acordei já estava com a música na minha cabeça, comecei a rabiscar pela parte da manhã e no horário de meio-dia fui para o tribunal com a introdução da música pronta e no tribunal montamos o meio da música. Mas isso ele atendendo e eu sentado ali, a gente pegava a pesquisa e íamos montando e o final foi feito em casa. A toada é feita em estrofe, às vezes colocávamos uma palavra que chamávamos de quebra galho e depois com auxílio dicionário íamos trocando (Entrevista de campo, setembro 2011).

A melodia criada por Ademar e seus parceiros resultou em quatro estrofes. Todo o processo de composição que foi desde a criação da letra, a elaboração do arranjo e a conclusão do CD durou três semanas. Para verificar como ficaria a canção, ele utilizou apenas o violão e, depois fez a primeira base do teclado e da bateria. No estúdio ABM, em Manaus, montou-se o violão I, violão II e violão III. Em seguida o charango, o contra-baixo, o surdo I, o 
surdo de corte e surdo de virada, além de efeitos de onças e de ventos, back. Por último incluíram a voz. Tal como podemos observar na letra a seguir.

\author{
Há hei, há hei
}

Estrondos, esturros, gritos, guerras

Onças, gatos, índios, feras

Vai começar o ritual dos caras de gato

Os martis ao redor da fogueira

Oferecem ao deus animal

Os tatuados

Bravos guerreiros ( $2 \mathrm{X}$ )

E rompe na maloca o mariwin, hê, he

Grita na aldeia o mariwin, hê, he ( $2 \mathrm{X}$ )

Criatura estranha de corpo

Untada de lama que vem pela beira

Coberta de folha de samambaia rasteira (2X)

Gigante mariwin a onça e o mariwin

A fera da aldeia assombra o curumim $(4 \mathrm{X})^{13}$

Ademar explica na primeira estrofe a maneira como imaginou o cenário de arena, isto é, as onças rajadas e abrindo a boca, emitindo esturros de animais ferozes. Diante da segunda estrofe pensa-se nas características dos índios Matis, iguais de um gato devido as suas pinturas. Enfatiza ainda, que é um ritual de passagem, onde um jovem passa para a fase adulta oferecendo um animal ao deus chamado Mariwin. Na terceira estrofe, o autor ressalta a consagração do ritual, quando o pajé pega o dente de onça ou da piranha para fazer o martírio no menino, e, em seguida entrega ao deus Mariwin. Nesta estrofe ele também relata o momento que o espírito chega para fazer a incorporação, vindo coberto de samambaia e lama.

Nesse ínterim, é perceptível que há uma relação entre a criação da toada com o cenário apresentado no bumbódromo. Dessa maneira, os compositores pesquisam elementos (plumárias, adornos, rituais) que fazem parte de determina etnia indígena e deslocam em forma de síntese para a composição das letras das toadas. Importante citar que os cenários utilizados no momento das apresentações principalmente no momento ritual, devem possuir relações coesas com as toadas que foram escolhidas durante os processos de seleção. 
Braga (2002) enfatiza:

As alegorias são trabalhos artísticos de grande proporção, envolvendo estruturas de tamanho e formas variáveis, que podem chegar a dez metros de largura e quatorze metros de altura. O tamanho das alegorias é limitado pelas proporções físicas dos galpões dos bois-bumbás (BRAGA, p. 101).

O primeiro artista plástico do Festival Folclórico de Parintins foi Jair Mendes. No fim da década de 1970 ele aprofundou seus conhecimentos e ganhou experiência trabalhando na construção de carros alegóricos nas escolas de samba do Rio de Janeiro, retomando a Parintins realizou suas primeiras participações como profissional no boi. A partir desse momento a padronização artística veio se sofisticando ao longo dos anos (BRAGA, 2002, 106).

Nesse aspecto, Lévi-Strauss (1989) atribui à arte, como mecanismo que se insere entre as duas formas de pensamento, seja ela primitiva ou científica. No entanto, o artista seria uma combinação movida pela ordem do sensível e do inteligível, ou seja, a ligação do conhecimento com a experiência. Nesse víeis, o autor diz:

[...] a arte se insere a meio caminho entre o conhecimento cientifico e o pensamento mítico ou mágico, pois todo mundo sabe que o artista tem, ao mesmo tempo, algo cientista e do bricoluer: com meios artesanais, ele elabora um objeto material que também um objeto de conhecimento (LÉVI-STRAUSS, 1989, p. 38).

É importante ressaltar, que o boi alegórico envolve um momento cuidadoso que sobressai em alguns dias de trabalho, nos meses que antecedem o festival. A preparação está relacionada, primeiramente, ao artifício da seleção das toadas. A partir daí escolhe-se o tema e logo em seguida criam-se as coreografias de palco e de arena ${ }^{14}$, depois o cenário alegórico, indumentárias e por fim os ensaios e a apresentação desse resultado na arena do bumbódromo.

No meu caso, pesquisar os bumbás de Parintins foi um obstáculo, estranhar tudo que é muito próximo/familiar, pesquisar/torcer e cantar/ 
dançar. A pergunta que veio sempre a tona é até que ponto pode-se ir mais longe, refletir, ampliar e conhecer. O pesquisador pode fazer parte e está acostumado com determinada situação ou até mesmo manter de certa forma uma relação com o grupo, mas não significa que compreenda a lógica de todas as suas interações.

Nesse meio tempo, a proximidade com o campo e com o nativo dificultou e ajudou ao mesmo tempo para o desenvolvimento da minha pesquisa. A dificuldade ocorreu na minha primeira viagem a campo, em que fui pressionada pelos membros da Comissão de Artes e do Conselho de Artes a aderir ou torcer por um boi, dificultando, dessa forma, o acesso às informações. Sendo assim, como adepta de um dos bois, me veio o questionamento em revelar ou não minha preferência. A saída por mim encontrada foi explicar que naquele momento não estava ali como "torcedora, mas sim, como pesquisadora".

As duas viagens de campo foram fundamentais para a execução deste trabalho, pois na medida em que coletava informações, era inevitável lembrarme da minha memória de quando morava em Parintins e, na medida em que isso acontecia, elas passavam por um processo de ressignificação e, nesse processo, vinham também possibilidades do "olhar de estranhamento" e a reflexão mais apurada da questão: de fato é necessário conhecer as diferences nuances que compõem o Festival Folclórico de Parintins.

\section{Considerações finais}

O Festival Folclórico de Parintins é um dos maiores festivais a céu aberto do Brasil e onde as atenções são direcionadas para a disputa de dois bumbás, Garantido e Caprichoso, no qual o vermelho e branco representam o primeiro e azul e branco representam o segundo. A disputa anual ocorre oficialmente na arena do bumbódromo, ao meio de camarotes, cadeiras e arquibancadas que são ocupados tanto por torcedores e admiradores que moram na cidade de Parintins quanto de outras partes do Brasil e do mundo que se a ela se deslocam para vivenciar o festival.

Anualmente o Boi Garantido escolhe seu tema em decorrência das letras das toadas entregues pelos compositores junto a Comissão de Artes. Esta realiza um certame que define as toadas do ano e, consequentemente, o 
tema a ser apresentado na arena, permitindo, dessa maneira, mais "liberdade" para o compositor durante o processo de criação. Já no Boi Caprichoso os procedimentos são diferenciados. Primeiramente o Conselho de Artes define as etnias indígenas que os compositores irão pesquisar para compor as toadas. Sendo assim, os compositores precisam, obrigatoriamente, citar as etnias previamente definidas. Dessa maneira, os compositores pesquisam e submetem suas toadas ao Conselho de Artes, que seleciona as que vão ser utilizadas durante o a apresentação no bumbódromo.

Nesse sentido, nota-se que a toada "Tucano" (MENCIUS MELO e INALDO MEDEIROS, 1995) foi criada quando os bois estavam passando por um procedimento de mudança no boi espetáculo, isto é, estava em voga a discussão em reuniões sobre uma nova forma de apresentar o boi na arena. Logo, o compositor nesse período escolhia a etnia pela sua expressividade ou mesmo pela sonoridade nas palavras que definiam as etnias indígenas. Portanto, não havia uma preocupação com pesquisas, sejam estas bibliográficas ou outras, tal como ocorre atualmente.

A toada "Mawirin" - 2004, autoria de Ademar Azevedo, David Jerônimo e Elaine Rodrigues, foi sistematizada por compositores que recentemente mais compõem toadas para os rituais dos bois-bumbas de Parintins. Hoje esses conteúdos musicais passam por seleções realizadas pela Comissão de Artes e Conselho de Artes dos bumbás; onde dos seus parâmetros utilizados é a fundamentação da pesquisa dos compositores mediante as etnias. Nesse sentido, no ato da submissão das toadas para a seleção, o compositor deve, obrigatoriamente, apresentar as referências bibliográficas - ou comprovações que o compositor fez pesquisa de campo, utilizadas na pesquisa e que o influenciaram no processo de criação.

Sendo assim, a disputa dos bois representa, na arena, uma disputa local que foi se constituindo com a própria história do festival. A toada é uma espécie de "ponte" que interliga a cultura indígena com a realidade dualística presente no cotidiano citadino de Parintins e, por mais que concordemos que esses elementos étnicos só estão interligados porque é necessário representar, de certa forma, essa disputa, só é possível a presença deles no festival de forma minimamente coesa se, antes de tudo, os compositores realizarem pesquisas que fundamentem suas respectivas composições. 


\section{Notas}

${ }^{1}$ Trabalho de monografia teve como universo de pesquisa os bumbás de Parintins (Garantido e Caprichoso) e nele discuti a presença indígena nas toadas dos rituais. Para fundamentação do estudo, foi feito um levantamento somente das toadas dos rituais, referente aos anos de 1995 a 2010, onde foram detectados vários povos indígenas, tal como os mais citados: Tucano/ Carajá/ Tupí-Guarani/ Kamayurá/ Saterê-Maué/ Munduruku/ Tupinambá/ Kaxinauá/ Apinayé/ Xicrin/ Mehinakus/ Yanomami/ Xavante/ Makú/ Tariana/ Wari/ Zuruahá/ Tapajós/ Baniwa/ Marubo/ Ashsninka/ Deni/ Katukina/ Kulina/ Mukaya/ Ikolen/ Mayoruna/ Matis/ Waimiri-Atroari. O processo de criação realizado pelos compositores, juntamente com seus arranjos elaborados passam por um processo de seleção da Comissão de Artes do boi Garantido e o Conselho de Artes do boi Caprichoso.

${ }^{2}$ São grandes cenários de produções artísticas apresentados na arena do bumbódromo.

${ }^{3}$ Cavalcanti (1999), Valentin (2005) e Rodrigues (2006).

${ }^{4}$ Parto da perspectiva em situar os currais como um todo, ou seja, quadra para ensaios, galpões, reuniões com integrantes que trabalham no boi e arena e outros.

${ }^{5}$ Segundo Dawsey, nos estudos de Turner, "a expressão performance deriva do francês parfournir, "completa" ou "realizar inteiramente" - refere-se, justamente, ao momento da expressão".

${ }^{6}$ Quem tira o verso é o Amo do Boi que representa o dono da fazenda, ressalta versos homenageando a torcida e também desafiando o boi adversário.

${ }^{7} \mathrm{O}$ espaço reúne arquibancadas laterais destinadas às torcidas organizadas ou galeras dos dois bumbás.

${ }^{8}$ A comissão nasceu de uma eleição realizada em 1998. No início a Comissão de Artes foi eleita com cinco membros: Fred Góes, Junho de Souza, Vandir Santos, Bosco Baré e Laura Teixeira, João Pedro coordenador da comissão e Telo Tinto, atual Presidente do Boi. A comissão atual é composta por 12 pessoas, incluindo também desenhistas e consultoria. (Pesquisa de campo, maio de 2011).

${ }^{9}$ Conselho de Artes do Caprichoso, 1992, é um órgão deliberativo vinculado à diretoria do boi, que tem plenos poderes de decisões. Seus primeiros membros foram: Márcia Baranda, Simão Assayag, Gil Gonsalves e Lene Medeiros, que eram um grupo pessoas que trabalhavam há muito tempo no caprichoso. No momento atual participam da escolha das toadas uma equipe de mais ou menos 20 pessoas, diretoria e convidados.

${ }^{10}$ Segundo Cavalcanti (1999), a presença indígena veio se intensificar na década de 1990, devido à expansão dos personagens no festival, a divulgação das toadas mediante o lançamento dos CDs de ambos os bumbás, ou seja, a produção comercial, a participação do Ministério da Cultura e das Empresas Patrocinadoras.

${ }^{11}$ Inaldo Cursino Medeiros compositor do Boi Garantido, entrevista de campo, setembro de 2011. 


\footnotetext{
${ }^{12}$ Fonte acessada no dia 16 de agosto de 2012http:/ / canalgarantido.com/

${ }^{13}$ Fonte acessada no dia 17 de agosto de 2012 http:/ / www.boicaprichoso.com/toadas

${ }^{14}$ As coreografias de palco são criadas para serem apresentadas no lançamento do CD/ DVD, e repetidas durante as festas no curral, diferentemente da coreografia para arena do bumbódromo que requer um trabalho de mais ou menos três meses de antecedência.
}

\section{Referências}

BRAGA, Sérgio Ivan Gil. Os bumbás de Parintins. Rio de Janeiro: Funarte/ Editora Universidade do Amazonas, 2002.

CAVALCANTI, Maria Laura Viveiro de Castro. Boi Bumbá de Parintins, Amazonas: breve história e uma etnografia da festa. Anais do XXIII Encontro Anual da ANPOCS. Caxambu/MG, 1999.

- Maria Laura Viveiros de Castro. Rivalidade e afeição: performances rituais no Bumbá de Parintins. Seminário Circuitos da Cultura Popular. Anais Eletrônicos. Rio de Janeiro, 2010.

. Maria Laura Viveiros de Castro. Os sentidos no espetáculo. In: Revista de Antropologia-USP, São Paulo, v. 45, n. 1, 2002. p. 37-78.

GEERTZ, Clifford. O saber local: novos ensaios em antropologia interpretativa. Tradução de Vera Melo Joscellyne. Petrópolis/RJ: Vozes, 1997.

LÉVI-STRAUSS, Claude. O pensamento selvagem. tradução: Tânia Pellegrine Campinas, SP: Papirus, 1989, p. 15-49.

. O cru e o cozido (Mitológicas v. 1). São Paulo: Cosac \& Naify. Abretura, 1964.

MENEZES BASTOS, Rafael José de. A 'Origem do Samba' como Invenção do Brasil (Por que as Canções têm Música?). In: Revista Brasileira de Ciências Sociais, v. 31, 1996, p. 156-177.

. Rafael José. Músicas nas Sociedades Indígenas nas Terras Baixas da America do Sul. Maná (2) 293-316, 2007.

RODRIGUES, Allan Soljenítsin Barreto. Boi Bumbá Evolução. Manaus: Editora Valer, 2006.

VALENTIN, Andreas. Contrários: a celebração da rivalidade dos Bois-Bumbás de Parintins. Manaus: Editora Valer, 2005. 
VELHO, Gilberto. Pesquisas urbanas: desafios de trabalho antropológico/ Gilberto Velho e Karina Kuschnir (org.). Rio de janeiro: Jorge Zahar. Edição 2003.

- O Desafio da cidade: novas perspectivas da antropologia brasileira. Rio de Janeiro: Campus, 1980.

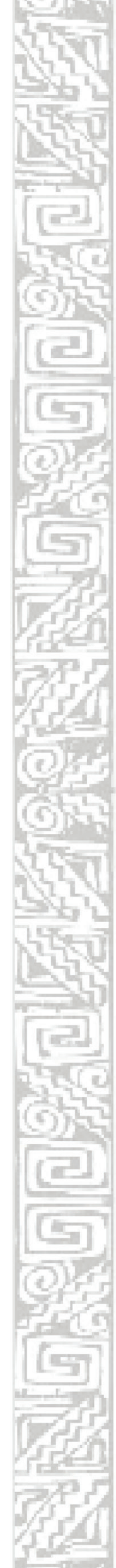

